\section{Einladung zur Mitgliederversammlung der DRG am Freitag, den 18. Mai 2012}

Zur ordentlichen Mitgliederversammlung der Deutschen Röntgengesellschaft, Gesellschaft für Medizinische Radiologie e.V (DRG), am Freitag, den 18. Mai 2012, von 13:30-15:00 Uhr im Congress-CentrumHamburg (CCH), lädt der Vorstand die Mitglieder der DRG hiermit herzlich ein.

\section{Tagesordnung}

- TOP 1 Begrüßung

- TOP 2 Totengedenken
- TOP 3 Genehmigung des Protokolls der Mitgliederversammlung vom 03. Juni 2011 (veröffentlicht im Jahresbericht 60, Januar 2012)

- TOP 4 Bericht des Präsidenten

- TOP 5 Bericht des Schatzmeisters

- TOP 6 Bericht der Kassenprüfer

- TOP 7 Vorschläge für Ehrungen 2013
- TOP 8 Entlastung des Vorstands

- TOP 9 Wahl der Kassenprüfer 2012

TOP 12 Wahl des Kongresspräsidenten 2015

- TOP 13 Einladung zum Röntgenkongress 2013

- TOP 14 Bericht der Akademie für Fortund Weiterbildung in der Radiologie, Verleihung der Wachsmann-Preise

- TOP 15 Bericht der Vorsitzenden der Vereinigung der Medizinisch-Technischen Berufe in der DRG (VMTB) 
- TOP 16 Bericht des Justitiars der DRG

- TOP 17 Verschiedenes

Im Namen des Vorstands

Prof. Dr. Michael Forsting (Präsident)

Zur Teilnahme an der Mitgliederversammlung ist die Vorlage des Mitgliedsausweises erforderlich. Entsprechend der Satzung der DRG können an der Mitgliederversammlung nur Mitglieder teilnehmen, deren Beitragskonto für 2012 ausgeglichen ist. 